\title{
REVIEW
}

\section{New Insights about miRNAs in Cystic Fibrosis}

\author{
Florence Sonneville, ${ }^{{ }^{\dagger}}$ Manon Ruffin, ${ }^{{ }^{\dagger}}$ Loïc Guillot, ${ }^{{ }^{\dagger}}$ Nathalie Rousselet, ${ }^{{ }^{\dagger}}$ Philippe Le Rouzic, ${ }^{{ }^{\dagger}}$ \\ Harriet Corvol, ${ }^{* \dagger}$ and Olivier Tabary ${ }^{* \dagger}$
}

From Inserm UMR_S938, * CDR Saint-Antoine, Paris; the Sorbonne Universités, ${ }^{\dagger}$ UPMC University Paris 06, Paris; and the Paediatric Respiratory Department, ${ }^{\ddagger}$ Hôpital Trousseau, AP-HP, Paris, France

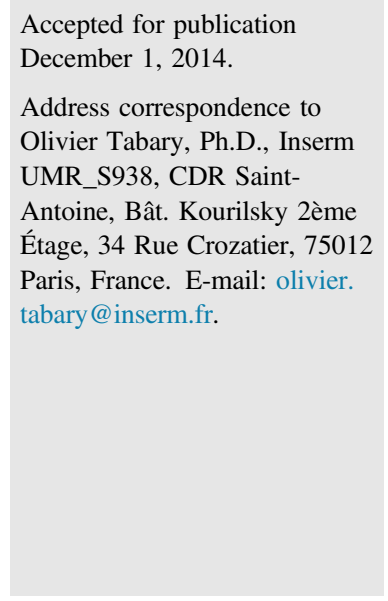

Accepted for publication

December 1, 2014. UMR S938, CDR SaintAntoine, Bât. Kourilsky 2ème Étage, 34 Rue Crozatier, 75012 Paris, France. E-mail: olivier tabary@inserm.fr.

\begin{abstract}
The molecular basis of cystic fibrosis (CF) is a mutation-related defect in the epithelial-cell chloride channel called CF transmembrane conductance regulator (CFTR). This defect alters chloride ion transport and impairs water transport across the cell membrane. Marked clinical heterogeneity occurs even among patients carrying the same mutation in the CFTR gene. Recent studies suggest that such heterogeneity could be related to epigenetic factors and/or miRNAs, which are small noncoding RNAs that modulate the expression of various proteins via post-transcriptional inhibition of gene expression. In the respiratory system, it has been shown that the dysregulation of miRNAs could participate in and lead to pathogenicity in several diseases. In CF airways, recent studies have proposed that miRNAs may modulate disease progression by affecting the production of either CFTR or various proteins that are dysregulated in the CF lung. Herein, we provide an overview of studies showing how miRNAs may modulate CF pathology and the efforts to develop miRNA-based treatments and/or to consider miRNAs as biomarkers. The identification of miRNAs involved in CF disease progression opens up new avenues toward treatments targeting selected clinical components of CF, independently from the CFTR mutation. (Am J Pathol 2015, 185: 897-908; http://dx.doi.org/10.1016/j.ajpath.2014.12.022)
\end{abstract}

The most common lethal genetic disorder in whites is cystic fibrosis $(\mathrm{CF})$. It is caused by mutations in the $\mathrm{CF}$ transmembrane conductance regulator $(C F T R)$ gene. More than 1900 pathogenic variants of this gene have been identified. The most common mutation $(70 \%)$ is an in-frame phenylalanine 508 deletion (F508del-CFTR) that induces severe lung disease attributed to impaired trafficking of the mutated CFTR protein to the plasma membrane (Figure 1). The CFTR protein is an apical chloride $\left(\mathrm{Cl}^{-}\right)$channel that not only participates directly in fluid homeostasis at the epithelium surface, but also regulates other $\mathrm{Cl}^{-}$channels, non- $\mathrm{Cl}^{-}$channels such as the epithelial $\mathrm{Na}^{+}$channel, and the transport of molecules, such as glutathione. ${ }^{1-3}$ Extensive studies on the CFTR gene and its protein have been conducted since its discovery and characterization in 1989 . $^{4}$ Nevertheless, the complex mechanisms which regulate CFTR expression remain poorly understood, and the sequence of CFTR-channel activation is empirical and unclear. Surprisingly, new treatments designed to correct the mutated CFTR protein defect have clearly focused the attention of some laboratories on defective CFTR processing and have greatly improved our knowledge of the CFTR channel. ${ }^{5,6}$

\section{Physiopathology}

In the CF pathology, morbidity and mortality are mainly related to self-perpetuating cycles of airway obstruction, infection, and inflammation. ${ }^{7}$ There is a pressing need for research into the sequence of events leading to progressive lung tissue damage, which remains incompletely understood. Initially, CFTR deficiency induces the loss of $\mathrm{Cl}^{-}$ secretion and the loss of epithelial $\mathrm{Na}^{+}$channel inhibition that leads to excess sodium and water reabsorption, resulting in dehydration of airway surface liquid compared to physiological situation (Figure 1, A and B). ${ }^{8}$ This imbalance

\footnotetext{
Supported by Inserm, UPMC-Paris 06 University, nonprofit organization Vaincre la Mucoviscidose, Legs Poix-Chancellerie des Universités-Paris, a Vaincre la Mucoviscidose Ph.D. grant (F.S.), and an Émergence-UPMC 2010 research program Ph.D. grant (M.R.).

Disclosures: None declared.
} 

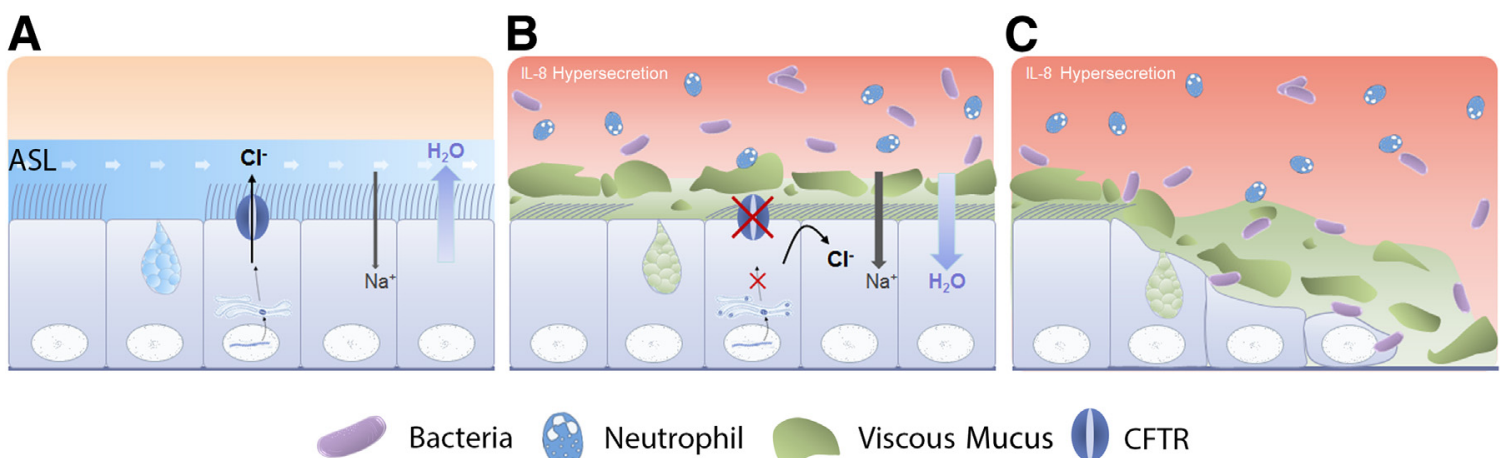

Neutrophil

Viscous Mucus

CFTR

Figure 1 Diagram comparing the non-cystic fibrosis (non-CF; A) and CF (B and C) pulmonary epithelium. A: The CF transmembrane conductance regulator (CFTR) defect causes hydromineral imbalance characterized by a decrease in the output of chloride ions ( $\left.\mathrm{Cl}^{-}\right)$, an increase in the entry of sodium ions ( $\mathrm{Na}^{+}$), and a dehydratation of the airway surface liquid (ASL) leading to a viscous mucus. B: The alteration of mucociliary clearance induced by viscous mucus promotes cycles of airway obstruction, infection by various pathogens, and inflammation characterized by neutrophil accumulation and IL-8 overproduction. C: IL-8 is consensually described as the marker of pulmonary inflammation in CF lungs; excessive neutrophil degranulation with inflammation damages the pulmonary epithelium.

results in the depletion of the airway surface liquid and in the increase of mucus viscosity that induces an impaired mucociliary clearance. In addition, infection and inflammation are observed and become persistent. Clinical data obtained during the past decade suggest that inflammation may precede infection, but this point is still debated. ${ }^{9,10}$ The F508del-CFTR mutation causes a massive proinflammatory phenotype in the lungs, characterized by an overexpression of chemoattractant molecules, such as IL-8, a proinflammatory cytokine whose expression is significantly increased in the $\mathrm{CF}$ airway and known as a marker of the pulmonary inflammation in CF. IL-8 is a well-known chemoattractant for neutrophil in the lung epithelium, participates in lung defense $\mathrm{7}^{7,9-12}$ (Figure $1, \mathrm{~B}$ and $\mathrm{C}$ ), and is a reference to evaluate $\mathrm{CF}$ airway inflammation. Many studies have demonstrated a crucial role for the transcription factor (TF) NF- $\kappa \mathrm{B}$ in the lung inflammation but have failed to identify a clear link between CFTR and NF- $\kappa \mathrm{B}$, despite some evidence implicating ionic homeostasis. ${ }^{713-16}$ Elucidating the mechanisms that underlie the inflammatory response might result in therapeutic improvements, thereby improving both the quality of life and length of survival of CF patients. In parallel, the lungs of children become chronically infected. Typically, infants are colonized by Haemophilus influenza and/or Staphylococcus aureus but quickly Pseudomonas aeruginosa becomes the predominant organism in the airways. ${ }^{17}$ This chronic infection perpetuates a vicious circle of infection and inflammation, leading to destruction and remodeling of the airway epithelium (Figure 1C), bronchiectasis, hypoxemia, hypercarbia, and, finally, pulmonary insufficiency. Despite remarkable advances in the knowledge achieved after the identification of the disease-causing gene, the clinical outcome for CF patients remains dependent on the gradual decline in lung function. Unfortunately, the mechanisms underlying the lung disease progression remain unclear, and the impact of polymorphisms throughout the genome complicates the outcome prediction. To date, minimal correlations have been found between CFTR genotype and disease severity, suggesting a role for environmental, stochastic, and genetic factors in the clinical heterogeneity of patients carrying the same mutation. ${ }^{18,19}$

\section{Treatments of CF Lung Disease}

CF lung treatment strategies target multiple steps in the progression of the pathology, including rehydration of the airway surface, mucolytics, anti-inflammatory agents, anti-infective agents, and, more recently, CFTR protein modulation. ${ }^{13}$

\section{Current Treatments}

Until now, CF has no cure, even if treatments have greatly improved life expectancy in past decades. ${ }^{13}$ The current lung disease treatments are symptomatic and proposed to treat $\mathrm{CF}$ lung pathology, fundamentally managing the consequences induced by the CFTR failure. One of the main treatments is the chest physical therapy, aiming at loosening and expectorating the excessive and hyperviscous airway mucus. To increase the mucus clearance, pharmacological treatments are also used, such as inhaled recombinant human DNase. ${ }^{14}$ The prevention and treatment of bacterial lung infections is deemed as a primary aim in CF. Improved antibiotic treatment strategies against airway infections are regarded as the main reason for the increased life expectancy of the $\mathrm{CF}$ patients in the past decade. ${ }^{20}$ Many CF centers try to eradicate airway bacteria colonization with several antibiotics, even in the absence of symptoms. Oral antibiotics are often used to treat mild lung infections. By contrast, inhaled antibiotics may be used to prevent or control infections due to the mucoid $P$. aeruginosa. For severe or hardto-treat infections, patients may be given i.v. antibiotics.

As outlined above, inflammation is a hallmark of CF lung pathology, ${ }^{7}$ and can be treated with drugs that have pleiotropic effects on cytokine secretion and/or neutrophils. Therefore, early trials of anti-inflammatory treatment have been done with 
corticosteroids, but serious adverse effects, such as glucose intolerance, bone demineralization, and growth delay, were observed. ${ }^{21}$ To improve the risk/benefit ratio, inhaled steroids could be prescribed, but benefits have not been shown clearly. ${ }^{22}$ Long-term macrolide antibiotic therapies are also prescribed to decrease CF lung inflammation. ${ }^{23}$ After evidence of a tremendous efficacy in diffuse panbronchiolitis, a disease that shares similarities with CF lung disease, they have been proposed in $\mathrm{CF}$ with great successes. The mechanism of efficacy of macrolides may be related to their antimicrobial, and antiinflammatory, properties, and specifically in $\mathrm{CF}$, to an activation of the chloride efflux. ${ }^{24,25}$ Among the several macrolides, azithromycin is the most used, with fewer adverse effects than other macrolides and dosing intervals. Other anti-inflammatory therapies proposed in CF are often confidential to a group or to a specific country. ${ }^{26}$

All these approaches are symptomatic, and do not directly target CFTR protein activity and/or the defective gene. In this context, new therapies that target the mutated CFTR protein to cure $\mathrm{CF}$ are under development.

\section{New Approaches to Correct CFTR}

Among the many evaluated strategies designed to correct $\mathrm{CF}$ abnormalities, only a few drugs targeting the mutated CFTR protein have shown meaningful efficiency to provide hope to the patients. These new drugs are small molecules that correct the trafficking and/or activity of the mutated CFTR. As introduced, several CFTR mutations lead to different mutated proteins. The most effective drug designed is a potentiator that targets CFTR gating mutations, by improving the channel opening probability, namely ivacaftor (VX-770; Vertex Pharmaceuticals Incorporated, Cambridge, MA). Although promising, ivacaftor is effective only in a few CF patients worldwide, because it has limited efficacy in patients carrying the F508del mutation. ${ }^{5,26-28}$ Preliminary results from two phase 3 trial studies using a combination of ivacaftor and a CFTR corrector (lumacaftor; VX-809; Vertex Pharmaceuticals Incorporated) have recently shown significant improvements in the lung function of patients homozygous for the CFTR F508del mutation, despite absence of proof-of-concept data. ${ }^{26}$ Some groups have also demonstrated that this strategy, combining potentiator and corrector, could be limited, and new strategies still need to be proposed. In fact, potentiators make CFTR less stable at the apical membrane. ${ }^{29,30}$ In this context, further research is needed to produce an array of strategies appropriate for all CFTR mutations. Thus, several groups have suggested that miRNA-targeted therapies might generate benefits by increasing CFTR chloride efflux. ${ }^{31-33}$ Further studies need to be conducted to produce new strategies appropriate for the various stages of CF disease.

\section{miRNA Data}

miRNAs are small (20 to 24 nucleotides) noncoding RNAs that regulate post-transcriptional gene expression. Since the identification of the first miRNA, lin-4, in the nematode Caenorhabditis elegans, $>1800$ miRNAs have been found in humans ${ }^{34,35}$ and listed in the database miRbase 21 (http:// www.mirbase.org, last accessed June 1, 2014). The miRNA biogenesis is well described. ${ }^{36-38}$ The miRNAs constitute a large family of phylogenetically conserved genes expressed in all cell types and tissues. The crucial role for miRNAs in protein regulation was recognized only recently. The full miRNA system may regulate $>60 \%$ of protein-coding genes in human cells, and miRNA dysregulation is involved in many lung diseases, including $\mathrm{CF} .{ }^{39-42}$

\section{Mechanisms of Action of miRNAs}

In numerous cases, miRNAs may provide a pleiotropic mechanism to explain the apparent complexity of different pathologies. Via a canonical pathway, miRNAs predominantly down-regulate the expression of their target genes by pairing with the $3^{\prime}$-untranslated regions (UTRs) of target mRNAs, thereby inducing mRNA degradation or translation inhibition. ${ }^{43}$ Thus, miRNA down-regulation results in increased protein expression of the targeted genes, whereas miRNA up-regulation represses their expression. This system of regulation, associated with TFs, allows a fine control of protein expression. The different possibilities and the complexity of these regulations are illustrated in Figure 2A. A TF can control the expression of different genes and/or miRNAs. The product of one gene can also control the expression of multiple miRNAs. However, one miRNA can influence the expression of different TFs and/or genes (Figure 2A). Recently, it has been proposed that miRNAs could directly bind DNA and, in the case of synonymous variants, alter a binding for miRNA and thereby modify the expression of the target gene ${ }^{44}$ (Figure 2, B and C). Modifications, such as mutations or polymorphisms, may change miRNA attachment and consequently inhibit expression of the protein of interest (Figure 2, B and C). Conversely, change in the $3^{\prime}$-UTR of an mRNA sequence can inhibit the binding of a miRNA and induce protein overexpression. In physiopathology, few variations could completely change the protein profile expression and therefore alter normal physiology.

Although the mechanisms underlying the effects of miRNAs are now well understood, the origin of miRNA dysregulation in disease is generally unknown. The mechanisms that control miRNA processing in specific cells and tissues need to be elucidated. The function and expression of mature miRNAs are controlled by mechanisms that regulate the processing of pri-miRNAs and pre-miRNAs. ${ }^{31}$ The complexity of the regulation system is important to recognize because each miRNA can target multiple mRNAs (Figure 2A). Each miRNA belongs to a multifactorial system of pathways subjected to many regulation systems. This extraordinary complexity substantially complicates efforts to understand the miRNA system and to offer simple 

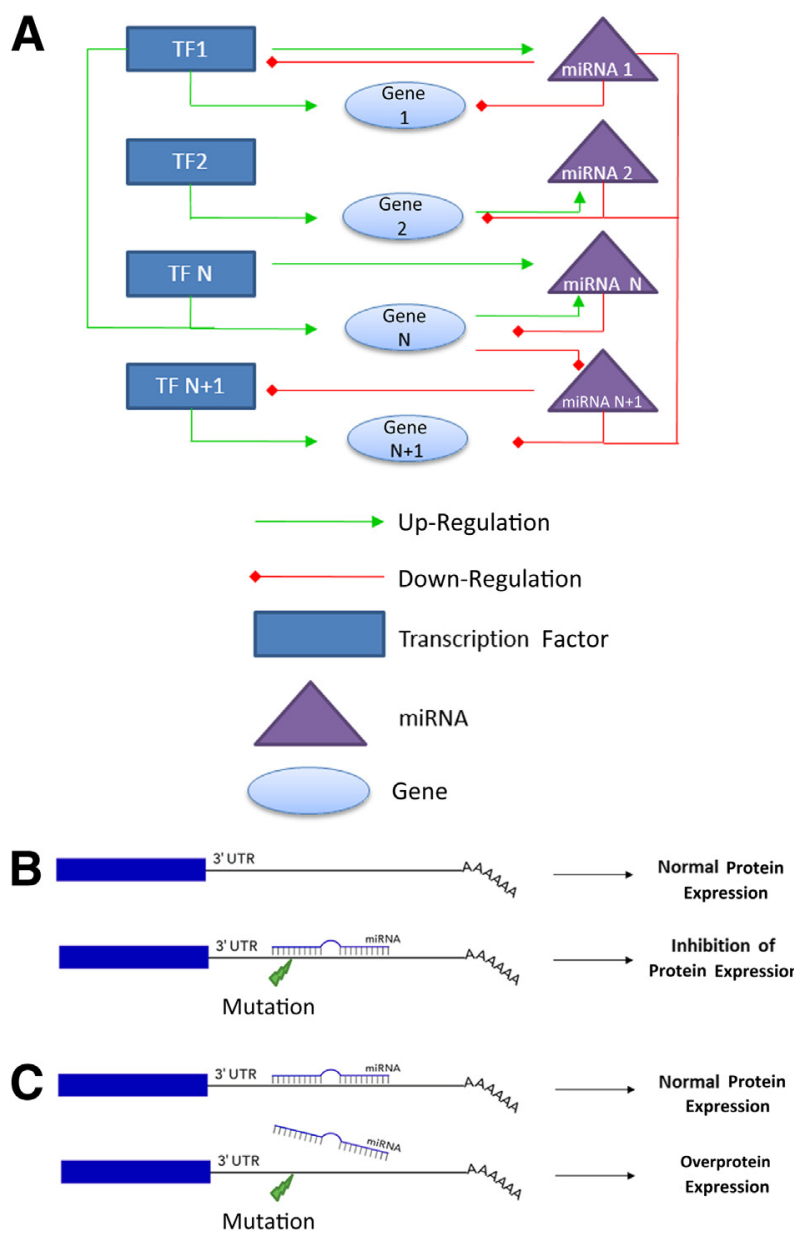

Figure 2 A: Diagram of interaction between miRNAs, genes, and transcriptional factor (TF) to regulate gene/protein expression. A miRNA regulates one or more genes, which are regulated by TFs that can also regulate the expression of other miRNAs. B and C: Mutation/polymorphism in the noncodant $3^{\prime}$-untranslated region (UTR) of a gene may modify the affinity of a miRNA for the $3^{\prime}$-UTR of the gene and, thus, alter the protein expression.

therapy. Because miRNAs are involved in the regulation of protein-coding gene expression, they play a role in many processes that induce disease states, such as cancer, and participate in CF pathology. ${ }^{45,46}$

\section{miRNA Target Prediction Tools}

Since the discovery of miRNAs in 1993, the view on gene expression regulation has started to change. Studies have been focused on predicting the target genes. This method is empirical and needs to be confirmed by biological experiments, whereas miRNome studies become easier. Two approaches have been used to study RNA regulation by miRNAs to determine the eventual link between miRNAs and RNAs.

First, the gene candidate approach is based on in silico analysis with bioinformatic databases predicting a score of miRNAs that could bind to RNAs of interest. It is important to use several bases because the results obtained are variable, depending on the criteria. Nowadays, different algorithms have been developed by different laboratories to predict miRNA-mRNA interaction, such as DIANAmicroT, TargetScan, miRWalk, miRanda, and PicTar. These algorithms are based not only on base pairing between miRNAs and the mRNA $3^{\prime}$-UTR, thermodynamic stability of miRNA-mRNA duplex, conservation of target sites, and free energy, but also on cooperative translational control and multiplicity of miRNA binding sites. ${ }^{47,48}$ The main algorithms used by the resources are artificial neural network, hidden Markov model, Naïve bayes, restricted baysesian, or support vector machine and could be combined to optimize the prediction. For example, TargetScan, one of the famous resources for miRNA-RNA interaction, used a restricted bayesian network model considering target position, conservation between species, and A-U-rich flanking regional accessibility. These different algorithms are used to avoid the many false-positive results obtained with the complementary sequence method.

The common practice for researchers is to look at predictions from several miRNA-target interaction algorithms and focus on their intersection; then, predictive results require validation by biological models. To illustrate this, we have predicted, using MirWalk software, ${ }^{49}$ without specific criteria, miRNAs that could bind CFTR and proteins that could bind these miRNAs (Figure 3A). miRNA targets were predicted by combinatorial use of five different web-based databases (miRanda, miRDB, miRwalk, RNA22, and TargetScan). The results were presented with Cytoscape software version 3.1.1. ${ }^{50}$ More than 49,000 proteins-half of all proteins expressed on human cells-are predicted to be regulated by miRNAs regulating CFTR. This example illustrates the importance of experimental in vitro and in vivo validation. Figure 3B shows the validated miRNAs regulating CFTR and represents only validated proteins regulated by these miRNAs. In this validated model, only 1132 proteins are presented. This example illustrates that predictions are just a tool before in vitro/in vivo validation.

Second, a data-driven prognostic method without a priori knowledge consisted of studying the differential expression of several miRNAs in CF and non-CF models. This comparison could be performed by different methods of miRNA expression profiling as microarray, miRNA sequencing, PCR arrays, and Fluidigm. In silico studies were then performed to determine whether the miRNAs overexpressed in CF were predicted to target CFTR.

As such, these two approaches are complementary and respond to different needs. Both methods have been used to find miRNAs implicated in the pathophysiology of CF.

\section{miRNAs and Genetic Diseases}

Considering that miRNAs can regulate the expression of numerous target genes, miRNAs are expected to regulate various physiological processes, including apoptosis, 


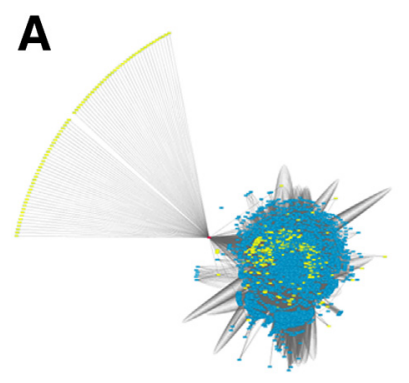

miRNAs PredictedProteins Predicted

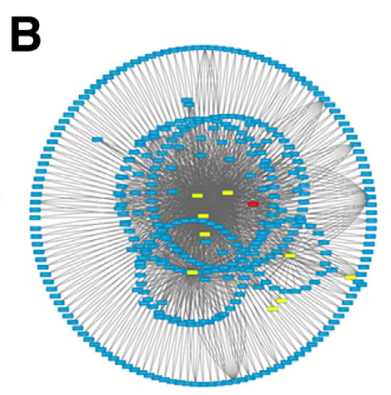

miRNAs Validated Proteins Validated

miRnA Regulating CFTR PFTR Proteins Regulated by miRNA

Figure 3 A and B: Network of cystic fibrosis transmembrane conductance regulator (CFTR; red) regulation mediated by miRNAs (yellow) that could influence the expression of other proteins. A: miRNAs predicted by in silico analysis to target CFTR (red) and other predicted proteins (blue). B: miRNAs demonstrated by in vivo experiments to regulate CFTR and known to regulate other proteins. C: miRNA target sequence location within the $3^{\prime}$-untranslated region (UTR) of the CFTR mRNA.

inflammation, differentiation, and proliferation. It is expected that mutations affecting miRNA function could have a pathogenic role in human genetic disease, similar to protein-coding genes. For example, numerous articles have shown that aberrant miRNA expression is implicated in numerous human cancers, but without a direct link between miRNAs and human genetic diseases. ${ }^{45,51,52}$ To date, there are no examples of mutations that are clearly associated with human mendelian disease because the regulation of miRNAs is redundant and a significant alteration of the function may elicit a minor perturbation of biological processes. Meola et $\mathrm{al}^{53}$ have well summarized and described three main types of mutation mechanisms affecting miRNA function: i) mutations affecting miRNAs directly, ii) mutations in the $3^{\prime}$-UTR of target mRNA, and iii) mutations in genes that participate in the process of miRNA function. In the first case, only two kinds of mutations affecting miRNAs have been described, mutations with a large sequence of genes affecting miRNAs ${ }^{53}$ or polymorphism in the seed sequence miRNA. ${ }^{54}$ In the case of mutation in the $3^{\prime}$-UTR, the first report identified two different sequences in the binding site of miR-189 in the $3^{\prime}$-UTR of the SLITRK1 mRNA in Tourette syndrome. ${ }^{55}$ Now, many articles have reported this kind of mutation affecting the regulation of mRNAs. In the last case of mutation, only few human mutations were described to participate in miRNA maturation. For example, one of this mutation affects DGGR8, a component of Drosha complex implicated in the maturation of miRNAs, which participates in DiGeorge syndrome. ${ }^{56} \mathrm{~A}$ complete loss of function of the core protein components of the miRNA processing is incompatible with life.

Altogether, the role of miRNAs in genetic diseases needs to be investigated more, especially in CF pathology.

\section{miRNAs and the Pathophysiology of CF}

Although many studies have focused on the role for miRNAs in regulating CFTR gene expression, little attention had been directed to other aspects, such as airway obstruction, inflammation, and infection.

\section{Regulation of CFTR by miRNAs}

Several groups are investigating the role for miRNAs in molecular pathways involved in the pathogenesis of CF. In particular, the regulation of expression by miRNAs of CFTR wild-type and mutated genes has been examined. Furthermore, the mRNA of CFTR is low abundant in airway epithelia, and miRNAs may silence low-abundance mRNA targets more efficiently than high-abundance mRNAs. ${ }^{32,57}$

By using in silico analyses, Gillen et $\mathrm{al}^{58}$ identified miRNAs that directly repressed $C F T R$ expression by binding to the $3^{\prime}$-UTR segment of the transcript. CFTR regulation seems to differ across the three cell lines used (Table 1). Interestingly, some miRNAs that repressed CFTR expression also targeted the $\mathrm{Na}^{+} / \mathrm{K}^{+} / \mathrm{Cl}^{-}$cotransporter $\mathrm{NKCC} 1$ channel, suggesting a general role for miRNAs in coordinating chloride transport and cell volume across epithelial cell membranes. miR-101 and miR-494 markedly repress CFTR expression in human embryonic kidney 293 cells when used alone, and the effect is considerably increased when the two miRNAs are combined. ${ }^{61}$ In silico analysis established that miR-101 and miR-494 can target other genes known to influence the disease severity of CF patients. A coordinated network of gene expression controlled by miRNAs has been suggested. ${ }^{61}$ In addition, air pollutants decrease the expression of CFTR and increase the expression of miR-101 and miR-144 in 16HBE14o- bronchial epithelial cells. Interestingly, miR-101 is up-regulated in the lung of patients with chronic obstructive pulmonary disease, a condition characterized by low levels of CFTR expression. ${ }^{63}$

This approach with RNA-miRNA is limited by prediction tools, and next-generation sequencing allows the analysis of different situations (eg, CF versus non-CF) without preconceived ideas. Two groups studied global miRNA expression in $\mathrm{CF}$ and non-CF models before performing in silico analyses. Interestingly, miR-138 has been predicted to target the TF SIN3A, which is able to bind the $C T C F$ binding sites of $C F T R{ }^{62}$ SIN3A is a target of miR-138 in airway epithelia, which regulates CFTR expression by suppressing SIN3A. Furthermore, miR-138 overexpression increases the expression and number of CFTR molecules reaching the cell surface, as well as 
Table 1 Deregulated Demonstrated miRNAs in Cystic Fibrosis and Their Targets

\begin{tabular}{|c|c|c|c|c|c|}
\hline Year & miRNA & $\begin{array}{l}\text { Direct } \\
\text { target }\end{array}$ & $\begin{array}{l}\text { Indirect } \\
\text { target }\end{array}$ & Cell types & Reference \\
\hline 2010 & miR-126 & TOM1 & & $\begin{array}{l}\text { Bronchial brushings, 16HBE140-, } \\
\text { CFBE410-, HEK293 }\end{array}$ & 42 \\
\hline \multirow[t]{2}{*}{2011} & $\operatorname{miR}-155$ & SHIP1 & IL-8 & IB3-1, S9 & 59 \\
\hline & $\begin{array}{l}\operatorname{miR}-494 \text {, miR-384, miR-376b, miR-1246, } \\
\text { miR-145, miR-331-3p, and miR-939 }\end{array}$ & CFTR & & Caco-2 & \\
\hline & miR-600, miR-494, miR-607, and miR-384 & CFTR & & 16HBE140- & \\
\hline & miR-101, miR-1246, miR-494, and miR-384 & $\mathrm{SLC} 12 \mathrm{~A} 2$ & & PANC-1 & \\
\hline 2011 & $\operatorname{miR}-449$ & Notch1 & & $\begin{array}{l}\text { Primary air-liquid interface cultures } \\
\text { of human airway epithelia }\end{array}$ & 60 \\
\hline 2012 & miR-101 and miR-144 & CFTR & & 16HBE140- & 63 \\
\hline 2013 & miR-145, miR-223, and miR-494 & CFTR & & $\begin{array}{l}\text { Bronchial brushings, 16HBE140-, } \\
\text { CFBE410-, HEK293 }\end{array}$ & 64 \\
\hline 2013 & $\operatorname{miR}-145$ & SMAD3 & & Nasal epithelium of patients with HEK293 & 65 \\
\hline 2013 & miR-509-3p and miR-494 & CFTR & & $\begin{array}{l}\text { Primary air-liquid interface cultures of } \\
\text { human airway epithelia; Calu3 }\end{array}$ & 32 \\
\hline
\end{tabular}

CFTR, cystic fibrosis transmembrane conductance regulator; SHIP, Src homology-2 domain-containing inositol 5-phosphatase 1 protein; TOM, translocase of the outer membrane.

CFTR activity in cells expressing not only wild-type CFTR, but also CFTR-F508del, thus opening therapeutic avenues for restoring CFTR function. ${ }^{62}$

A direct link between miRNAs and CFTR expression in CF has been reported. ${ }^{64}$ CFTR is directly regulated by miR-145, miR-223, and miR-494 when used alone, with a synergistic effect of combinations of these miRNAs. Furthermore, deficient CFTR channel activity is a possible cause of the overexpression of miR-145, miR-223, and miR-494 in CF. ${ }^{64}$ Recently, miR-509-3p and miR-494 have been identified as post-transcriptional CFTR repressors that act synergistically to produce larger effects in $\mathrm{CF}$. There is a reported link between the expression of the two miRNAs and CFTR function. ${ }^{32}$

However, the system of CFTR regulation by miRNAs seems more complex, with numerous parameters not yet elucidated. The regulation of $C F T R$ changes before and after birth; the CFTR gene undergoes tissue-specific and temporal changes in expression. ${ }^{66}$ This regulation is tightly controlled by TFs and miRNAs. To increase complexity, gene mutation in miRNA targeting sites of CFTR could be a new pathogenetic mechanism in $\mathrm{CF}^{67}$ Three singlenucleotide polymorphisms, one of which is located in a region predicted to bind miR-433 and miR-509 and causes a small decrease in CFTR protein expression due to enhanced binding of miR-509-3p, have been identified (Figure 2, B and C). Further studies need to be performed to understand the effects of miRNA on the CFTR gene. The discussed studies illustrate the complex mechanisms by which miRNAs convey functional binding to CFTR mRNA targets. We have summarized in Figure 3C demonstrated binding sites of miRNAs regulating CFTR in pulmonary cells. Extensive analysis needs to be conducted before proposing miRNAs as therapeutic targets.

\section{miRNAs, Inflammation, and CF}

Chronic airway inflammation is a major component of $\mathrm{CF}$ pathophysiology. The genesis of this inflammation remains unclear but could involve miRNAs. Different approaches have been used to assess the role for miRNAs in $\mathrm{CF}$ inflammation.

A global approach to identify miRNAs that were dysregulated in CF provided the first set of evidence. ${ }^{42}$ miR-126 was found to be down-regulated in CF compared to the non-CF models in vivo and in vitro. Results showed that miR126 targets the IL-1R1 and Toll-like receptor 2 and 4 signaling inhibitor translocase of the outer membrane 1 and the NF- $\kappa B$ pathway.

An expression screen of a miRNA library in F508delCFTR and wild-type CFTR lung epithelial cell lines identified miRNAs associated with the proinflammatory phenotype in the CF lung. ${ }^{59} \mathrm{miR}-155$ is up-regulated in $\mathrm{CF}$ cells, both in vitro and in vivo, and there is a link between CFTR activity and miR-155 expression. By using bioinformatics analysis and in vitro cell-line experiments, a direct link between the levels of miR-155 and those of Src homology-2 domain-containing inositol 5-phosphatase 1 
protein was established. This relationship indirectly affects IL-8 protein expression via phosphatidylinositol 3-kinase/ Akt pathway activation and downstream mitogen-activated protein kinase signaling activation. miR-155 overexpression in $\mathrm{CF}$ is mediated by the RNA-binding proteins tristetraprolin and $\mathrm{KH}$-type splicing regulatory protein, known to regulate miRNA processing. ${ }^{31}$ In studies evaluating inflammation, IL-8, and the TF NF- $\mathrm{BB}$ in $\mathrm{CF}$, a binding site for NF- $\kappa \mathrm{B}$ at the $5^{\prime}$-UTR segment of two CFTR-regulating miRNAs was identified. CFTR expression and function decrease to a larger extent when NF- $\kappa$ B is functional. ${ }^{32}$ Thus, inflammatory processes under $\mathrm{NF}-\kappa \mathrm{B}$ control influence miRNA expression, through an unknown mechanism, thereby regulating CFTR expression and function. Another proinflammatory profile in CF is linked to dysregulation of the transforming growth factor$\beta 1$ signaling pathway via SMAD3 proteins. By using a candidate miRNA approach, miR-145 was found to regulate SMAD3 expression in human embryonic kidney 293 cells. miR-145 and SMAD3 mRNA levels negatively correlate in nasal respiratory epithelial cells from $\mathrm{CF}$ patients. ${ }^{65}$ SMAD3 is a protein that protects against infections and inflammation. These studies documenting a link between miRNAs and CF inflammation suggest new ways of developing treatment strategies to decrease inflammation in CF patients.

\section{Regulation of CF Lung Obstruction and Infection by miRNAs}

Loss of homeostasis of airway surface liquid volume in patients with CF may impair mucus structure, clearance, and airway defenses. In the airway epithelium, CFTR abnormalities cause dehydration of the mucus, which becomes thick and viscous, impairing mucociliary clearance and affecting respiratory function. Thus, elucidating airway mucus regulation is a current research objective. The MUC5AC mucin is a major airway mucus component whose production is stimulated by neutrophil elastase. miR-146a decreases the production of MUC5AC. ${ }^{68}$ Thus, miR-146a may be involved in controlling mucus secretion by human bronchial epithelial cells. The role for MUC5AC expression is highly controversial, although some evidences point to an effect on the severity of CF lung disease. ${ }^{69} \mathrm{~A}$ better understanding of this protein regulation in physiological context could be essential to adapt the treatment of CF patients.

To investigate the hypothesis that miRNAs are important regulators of multiciliogenesis in vertebrates, Marcet et $\mathrm{al}^{60}$ studied the miRNA expression profile before and after multiciliogenesis in both primary cultures of differentiated human airway mucociliary epithelial cells grown at an air-liquid interface, and in the mucociliary epidermis of Xenopus embryos. Interestingly, the same miRNA, miR449 , is up-regulated during multiciliogenesis in both models and promotes multiciliogenesis by directly repressing the Delta/Notch pathway known to be associated with cell proliferation and differentiation. The thick viscous mucus in $\mathrm{CF}$ airways encourages local colonization by various pathogens, such as $H$. influenza, $S$. aureus, and $P$. aeruginosa. Only a few groups are working on links between miRNAs and the innate immune response, which is the first line of defense against infections by exogenous pathogens. In CF, the expression of miRNAs targeting CFTR increases ${ }^{32,64}$; the presence of pathogens in the $\mathrm{CF}$ airway epithelium modulates the expression of miRNAs, which, in turn, regulates CFTR. The expression of miR-93 and IL-8 is correlated during $P$. aeruginosa infection in bronchial epithelial cells, and a combined treatment based on the use of different premiRNAs has been proposed to achieve high efficiency. ${ }^{70}$

In Table 1, we have summarized the different deregulated miRNAs that have been shown to regulate CFTR and other proteins in the context of CF. Altogether, these data indicate new mechanisms that may influence the expression of CFTR and the development of CF pathology. This first step of research has led to new therapeutics, to specifically target CFTR protein.

\section{Perspectives}

\section{miRNAs as Biomarkers}

A major clinical problem in $\mathrm{CF}$ is the absence of a specific biomarker for monitoring and/or predicting lung disease progression. Spirometry measurements constitute the reference standard to date. The forced vital capacity and forced expiratory volume in 1 second, although widely used to assess disease progression, are affected by multiple lung changes, such as inflammation, infection, and respiratory epithelium damage. The most relevant techniques for assessing inflammation and cell functions are invasive and cannot be used in regular clinical practices. In this context, epigenetics, and particularly miRNAs, as one of the important epigenetic mechanisms that regulate gene expression, should constitute a promising field for the development of biomarkers in the comprehension of $\mathrm{CF}$.

For several diseases, identifying biomarkers and improving the diagnosis are key challenges for researchers and clinicians. Various miRNAs have emerged as crucial posttranscriptional gene expression regulators involved in many normal and pathological processes. Several characteristics of miRNAs suggest their usefulness as biomarkers, despite the uncertain role of these circulating miRNAs in biological functions.

miRNAs are extremely resistant to degradation, so miRNAs are ideal candidates as biomarkers for cancer diagnostics. Thus, different groups have found that miRNAs are highly stable in serum or plasma, despite the presence of high levels of ribonuclease activity in blood. For example, incubation of plasma at room temperature for up to 24 hours led to no decrease in the level of circulating miRNAs; more miRNAs present in serum are insensible to modification of $\mathrm{pH}^{71,72}$ 
The measurement of miRNAs in body fluid has high potential for future noninvasive diagnostic tests and can be detectable in easily accessible body fluid like peripheral blood. Interestingly, miRNAs are also present in other body fluids, such as the sputum, saliva, and urine.$^{73}$ miRNAs are stably present in sputum, and lung adenocarcinoma patients can be differentiated from healthy individuals by using a panel of four sputum miRNAs. ${ }^{74}$ Furthermore, differences in the serum miRNA expression pattern correctly separate healthy individuals and patients with various diseases, including lung cancer. ${ }^{45,75-77}$

In human peripheral blood, miRNAs are detectable not only in serum or plasma, but also in the cellular fraction. Consequently, miRNA expression can be assessed using simple and affordable molecular biology tools available to laboratories, such as quantitative PCR, and it could be easy to observe the evolution of the pathology at different stages of the illness.

These arguments have led many groups, especially in the field of cancer, to evaluate miRNAs as diagnostic or prognostic biomarkers. ${ }^{78}$ These studies are numerous and may be partially applied to the CF domain. The use of miRNAs as minimally invasive biomarkers has generated new opportunities for the diagnosis and prognosis of cancer because they exhibit tumor-specific expression in blood of patients with cancer. The first miRNA aberrantly expressed in lung cancer was identified in $2004 .{ }^{79}$ A low level of let-7 expression is significantly associated with poor survival in patients with surgically resected non-small cell lung cancer, suggesting a prognostic role for miRNA assays. A recent multicenter study established that different types of malignant or nonmalignant diseases could be differentiated on the basis of blood-borne miRNA profiles. ${ }^{80}$ The miRNA expression levels may also serve as indicators of drug responses in lung cancer. ${ }^{81}$ The miRNA pathways involved in several molecular processes will probably be elucidated in the near future to avoid conflicting studies in terms of the miRNAs associated with patient survival.

Despite promising data, no studies have clearly demonstrated the importance of miRNAs as biomarkers in CF. A decrease in the cost of RNA profiling and increased availability of RNA and miRNA profiling should allow the development of standardized protocols. These new insights and the increasing knowledge about the role for miRNAs will help to develop novel miRNA-based therapeutic approaches.

\section{miRNAs as Therapeutics}

It is well accepted that aberrant miRNA expression can occur in various diseases, including lung cancer. Modulators of miRNA expression may, therefore, produce benefits in lung diseases. ${ }^{82}$ There are two main obstacles to this treatment approach. To avoid or minimize adverse effects, one or a few relevant targets must be identified, and therefore the pathophysiology of CF must be fully elucidated. The most appropriate cells must be effectively targeted.

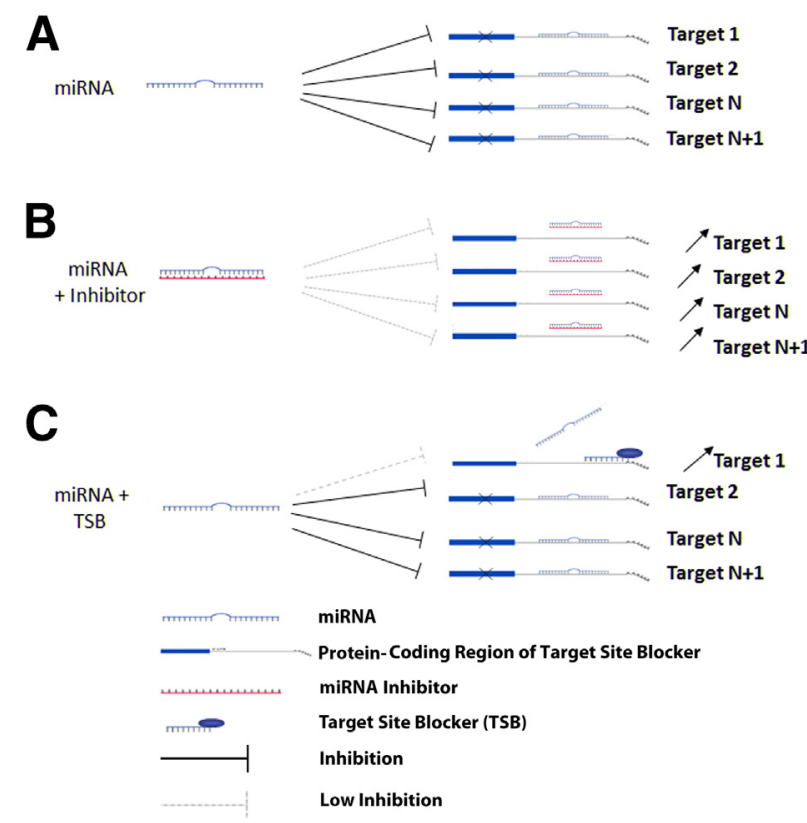

Figure 4 A: One miRNA binds to the $3^{\prime}$-untranslated region (UTR) of many mRNAs, and consequently may inhibit mRNA translation or mRNA degradation of these targets. B: Specific miRNA inhibition may result in an increased expression of all of the targets. C: Specific inhibition of the target site of one miRNA by a modified oligonucleotide may further prevent inhibition of other miRNA targets.

Initial research focused on nucleic acid-based treatments with antisense molecules, including ribozyme, aptamer, and siRNAs. Most of the approaches used to target mRNA sequences rely on RNase H-mediated mRNA degradation on binding to a complementary DNA oligonucleotide. ${ }^{83}$ In $\mathrm{CF}$, considerable hope was placed for many years in gene therapy to deliver copies of the wild-type CFTR DNA coding sequence to target cells. Since the 1990s, however, research into gene therapy has failed to provide clear evidence of clinical benefits, and no gene therapies have been approved by regulatory authorities. The main problems have been limited efficacy of the gene transfer vector, short-lived gene expression, and adverse effects with both viral and nonviral techniques. ${ }^{84}$

miRNAs are more promising methods of gene correction than other molecules, for many reasons. They are smaller, less antigenic, and easier to insert into cells, compared to their protein-coding counterparts. Although DNA-based approaches require delivery to the nucleus, miRNAs only need to be delivered to the cytoplasm, and the inhibition results in subsequent miRNA degradation and, thus, the up-regulation of target that can be maintained for $>3$ weeks. ${ }^{34,75}$ Another advantage of miRNAs is the limited need for high-strand complementarity.

Modulation of miRNAs is now more currently used in basic science to elucidate the mechanisms underlying mRNA function. To date, in vivo therapeutic studies have used only single miRNAs, but combinations of miRNAs will be evaluated in the future. Different studies and patents proposed, with the recent development of advanced nebulizers, airway nebulization of miRNAs to more specifically target airway epithelial cells, but the result is highly carrier dependent and 
new technologies are needed to increase the yield. ${ }^{33} \mathrm{In} C \mathrm{CF}$, the ideal target is CFTR and corrective effects should occur for all CFTR mutation variants, without inducing adverse effects. $^{85}$

Interestingly, low levels of gene transfer of CFTR to airway epithelia are sufficient to correct chloride transport in vitro and in vivo. ${ }^{86-89}$ Recently, a group cultured $10 \%$ of wild-type or corrected cells mixed with $90 \%$ of CF cells. The authors demonstrated that the $10 \%$ of normal cells were sufficient to normalize the main dysregulated parameters, such as $\mathrm{Cl}^{-}$or $\mathrm{Na}^{+}$conductance and IL-8 secretion. ${ }^{90}$ In a concept of gene therapy, this ability to correct the CF parameters by correcting few cells is important, because it is well known that it will be impossible to correct all of the cells of the lungs of CF patients. Furthermore, targeting other $\mathrm{Cl}^{-}$channels, such as the calcium-activated chloride channel called ANO1, may hold promise to compensate for the loss of CFTR $\mathrm{Cl}^{-}$activity and the abnormal repair process. ${ }^{91}$ However, all other dysregulated proteins in $\mathrm{CF}$ could also constitute targets to correct imbalances in physiological parameters. Typically, miRNAs regulate gene expression of multiple targets (Figure 4A). Inhibition of the miRNAs will result in derepression of all these targets and increase the possibility of adverse effects in the use of miRNAs as therapeutic targets (Figure 4B). An interesting approach in therapeutics is to use interfering miRNA-target interactions, which are antisense oligonucleotides that bind to the miRNA target site of an mRNA, thereby preventing miRNAs from gaining access to that site (Figure 4C).

A single miRNA-based treatment is currently used in clinical practice and targets the specific liver-expressed miR-122 using the locked nucleic acid-modified antisense oligonucleotide. After a study on chimpanzees showing that locked nucleic acid-modified anti-miRNAs are specific, nontoxic, and stable, miravirsen has been used for treatment of hepatitis $\mathrm{C}$ virus infection and shows prolonged dose-dependent reductions in hepatitis C virus RNA levels in patients with chronic hepatitis $\mathrm{C}$ virus infection. ${ }^{92}$ Other miRNA-based treatments are being developed.

In CF, it would be interesting to block the target site(s) of miRNA(s) in the $3^{\prime}$-UTR of CFTR to avoid miRNA inhibition. Respiratory involvement being predominant, it might be possible to give the miRNA target site blockers to patients by inhalation to avoid adverse effects in other organs. Understanding the mechanism of miRNA function is crucial to identify the best approach for drug design. There is much interest in identifying the role of miRNAs in the modulation of drug responses, but limited studies have been reported. Studies on miRNAs and pharmacogenomics also hold promise for improving the treatment of CF patients.

\section{Conclusion}

The latest research shows that miRNAs exert crucial effects on gene regulation and may play a prominent role in cell physiology. Improved understanding of the sequence of events has already allowed the use of miRNAs for diagnostic and prognostic purposes and, more specifically, for detecting susceptibility to certain cancers. Currently, the clinical use of miRNAs remains limited, but major changes can be expected in the near future. New tools can specifically target sequences of interest and resolve problems associated with the multiplicity of targets. The main hurdle is identification of miRNAs that target proteins or pathways of interest. In CF, CFTR mRNA is a promising target, because the first studies have shown that miRNAs can modulate the normal or mutated CFTR protein. In contrast, current treatments target only specific CFTR mutations. Although many studies have established the usefulness of miRNAs in targeting CFTR, further research is needed to identify the miRNA combination that best corrects the abnormalities without inducing adverse effects. Similarly, the best concentrations and dosing schedules need to be determined. Promising data from preclinical studies indicate that miRNA treatments will be evaluated in patients with $\mathrm{CF}$.

Thus, miRNA therapy is a fascinating and dynamic field of research in CF. The future can be expected to establish a major role for miRNAs as therapeutic agents or diagnostic tools for CF patients.

\section{References}

1. Schwiebert EM, Egan ME, Hwang TH, Fulmer SB, Allen SS, Cutting GR, Guggino WB: CFTR regulates outwardly rectifying chloride channels through an autocrine mechanism involving ATP. Cell 1995, 81:1063-1073

2. Rubenstein RC, Lockwood SR, Lide E, Bauer R, Suaud L, Grumbach Y: Regulation of endogenous ENaC functional expression by CFTR and $\triangle$ F508-CFTR in airway epithelial cells. Am J Physiol Lung Cell Mol Physiol 2011, 300:L88-L101

3. Linsdell P, Hanrahan JW: Glutathione permeability of CFTR. Am J Physiol 1998, 275:C323-C326

4. Riordan JR, Rommens JM, Kerem BS, Alon N, Rozmahel R, Grzelczak Z, Zielenski J, Lok S, Plavsic N, Chou J-L, Drumm ML, Iannuzzi MC, Collins FS, Tsui L-C: Identification of the cystic fibrosis gene: cloning and characterization of complementary DNA [Erratum appeared in Science 1989, 245:1437]. Science 1989, 245: 1066-1073

5. Van Goor F, Hadida S, Grootenhuis PD, Burton B, Stack JH, Straley KS, Decker CJ, Miller M, McCartney J, Olson ER, Wine JJ, Frizzell RA, Ashlock M, Negulescu PA: Correction of the F508del-CFTR protein processing defect in vitro by the investigational drug VX-809. Proc Natl Acad Sci U S A 2011, 108:18843-18848

6. Ren HY, Grove DE, De La Rosa O, Houck SA, Sopha P, Van Goor F, Hoffman BJ, Cyr DM: VX-809 corrects folding defects in cystic fibrosis transmembrane conductance regulator protein through action on membrane-spanning domain 1. Mol Biol Cell 2013, 24: 3016-3024

7. Jacquot J, Tabary O, Clement A: Hyperinflammation in airways of cystic fibrosis patients: what's new? Expert Rev Mol Diagn 2008, 8: 359-363

8. Boucher RC: Evidence for airway surface dehydration as the initiating event in CF airway disease. J Intern Med 2007, 261:5-16

9. Tabary O, Zahm JM, Hinnrasky J, Couetil JP, Cornillet P, Guenounou M, Gaillard D, Puchelle E, Jacquot J: Selective up-regulation of chemokine 
IL-8 expression in cystic fibrosis bronchial gland cells in vivo and in vitro. Am J Pathol 1998, 153:921-930

10. Tirouvanziam R, Khazaal I, Peault B: Primary inflammation in human cystic fibrosis small airways. Am J Physiol Lung Cell Mol Physiol 2002, 283:L445-L451

11. Tabary O, Escotte S, Couetil JP, Hubert D, Dusser D, Puchelle E, Jacquot J: Genistein inhibits constitutive and inducible NFkappaB activation and decreases IL-8 production by human cystic fibrosis bronchial gland cells. Am J Pathol 1999, $155: 473-481$

12. Tabary O, Escotte S, Couetil JP, Hubert D, Dusser D, Puchelle E, Jacquot J: High susceptibility for cystic fibrosis human airway gland cells to produce IL-8 through the I kappa B kinase alpha pathway in response to extracellular $\mathrm{NaCl}$ content. J Immunol 2000, 164: $3377-3384$

13. Davies JC, Ebdon AM, Orchard C: Recent advances in the management of cystic fibrosis. Arch Dis Child 2014, 99:1033-1036

14. Rowe SM, Clancy JP: Advances in cystic fibrosis therapies. Curr Opin Pediatr 2006, 18:604-613

15. Tabary O, Muselet C, Miesch MC, Yvin JC, Clement A, Jacquot J: Reduction of chemokine IL-8 and RANTES expression in human bronchial epithelial cells by a sea-water derived saline through inhibited nuclear factor-kappaB activation. Biochem Biophys Res Commun 2003, 309:310-316

16. Tabary O, Muselet C, Yvin JC, Halley-Vanhove B, Puchelle E, Jacquot J: Physiomer reduces the chemokine interleukin-8 production by activated human respiratory epithelial cells. Eur Respir J 2001, 18: 661-666

17. O'Sullivan BP, Freedman SD: Cystic fibrosis. Lancet 2009, 373: $1891-1904$

18. Cutting GR: Modifier genes in Mendelian disorders: the example of cystic fibrosis. Ann N Y Acad Sci 2010, 1214:57-69

19. Corvol H, Beucher J, Boelle PY, Busson PF, Muselet-Charlier C, Clement A, Ratjen F, Grasemann H, Laki J, Palmer CN, Elborn JS, Mehta A: Ancestral haplotype 8.1 and lung disease severity in European cystic fibrosis patients. J Cyst Fibros 2012, 11:63-67

20. Sherrard LJ, Tunney MM, Elborn JS: Antimicrobial resistance in the respiratory microbiota of people with cystic fibrosis. Lancet 2014, 384:703-713

21. Eigen H, Rosenstein BJ, FitzSimmons S, Schidlow DV: Cystic Fibrosis Foundation Prednisone Trial Group: A multicenter study of alternate-day prednisone therapy in patients with cystic fibrosis. J Pediatr 1995, 126:515-523

22. Balfour-Lynn IM: Cystic fibrosis papers of the year 2009. J R Soc Med 2009, 103(Suppl 1):S6-S14

23. Yousef AA, Jaffe A: The role of azithromycin in patients with cystic fibrosis. Paediatr Respir Rev 2010, 11:108-114

24. Saint-Criq V, Rebeyrol C, Ruffin M, Roque T, Guillot L, Jacquot J, Clement A, Tabary O: Restoration of chloride efflux by azithromycin in airway epithelial cells of cystic fibrosis patients. Antimicrob Agents Chemother 2011, 55:1792-1793

25. Balloy V, Deveaux A, Lebeaux D, Tabary O, le Rouzic P, Ghigo JM, Busson PF, Boëlle P, Guez JG, Hahn U, Clement A, Chignard M, Corvol H, Burnet M, Guillot L: Azithromycin analogue CSY0073 attenuates lung inflammation induced by LPS challenge. Br J Pharmacol 2014, 171:1783-1794

26. Hoffman LR, Ramsey BW: Cystic fibrosis therapeutics: the road ahead. Chest 2013, 143:207-213

27. Van Goor F, Hadida S, Grootenhuis PD, Burton B, Cao D, Neuberger T, Turnbull A, Singh A, Joubran J, Hazlewood A, Zhou J, McCartney J, Arumugam V, Decker C, Yang J, Young C, Olson ER, Wine JJ, Frizzell RA, Ashlock M, Negulescu P: Rescue of CF airway epithelial cell function in vitro by a CFTR potentiator, VX-770. Proc Natl Acad Sci U S A 2009, 106:18825-18830

28. Yu H, Burton B, Huang CJ, Worley J, Cao D, Johnson JP Jr, Urrutia A, Joubran J, Seepersaud S, Sussky K, Hoffman BJ, Van
Goor F: Ivacaftor potentiation of multiple CFTR channels with gating mutations. J Cyst Fibros 2012, 11:237-245

29. Cholon DM, Quinney NL, Fulcher ML, Esther CR Jr, Das J, Dokholyan NV, Randell SH, Boucher RC, Gentzsch M: Potentiator ivacaftor abrogates pharmacological correction of DeltaF508 CFTR in cystic fibrosis. Sci Transl Med 2014, 6:246ra96

30. Veit G, Avramescu RG, Perdomo D, Phuan PW, Bagdany M, Apaja PM, Borot F, Szollosi D, Wu YS, Finkbeiner WE, Hegedus T, Verkman AS, Lukacs GL: Some gating potentiators, including VX770, diminish DeltaF508-CFTR functional expression. Sci Transl Med 2014, 6:246ra97

31. Bhattacharyya S, Kumar P, Tsuchiya M, Bhattacharyya A, Biswas R: Regulation of miR-155 biogenesis in cystic fibrosis lung epithelial cells: antagonistic role of two mRNA-destabilizing proteins, KSRP and TTP. Biochem Biophys Res Commun 2013, 433:484-488

32. Ramachandran S, Karp PH, Osterhaus SR, Jiang P, WohlfordLenane C, Lennox KA, Jacobi AM, Praekh K, Rose SD, Behlke MA, Xing Y, Welsh MJ, McCray PB Jr: Post-transcriptional regulation of cystic fibrosis transmembrane conductance regulator expression and function by microRNAs. Am J Respir Cell Mol Biol 2013, 49: 544-551

33. McKiernan P, Cunningham O, Greene C, Cryan S: Targeting miRNA-based medicines to cystic fibrosis airway epithelial cells using nanotechnology. Int J Nanomedicine 2013, 8:3907-3915

34. Lee RC, Feinbaum RL, Ambros V: The C. elegans heterochronic gene lin-4 encodes small RNAs with antisense complementarity to lin-14. Cell 1993, 75:843-854

35. Griffiths-Jones S, Grocock RJ, van Dongen S, Bateman A, Enright AJ: miRBase: microRNA sequences, targets and gene nomenclature. Nucleic Acids Res 2006, 34:D140-D144

36. Erson-Bensan AE: Introduction to microRNAs in biological systems. Methods Mol Biol 2014, 1107:1-14

37. Denli AM, Tops BB, Plasterk RH, Ketting RF, Hannon GJ: Processing of primary microRNAs by the Microprocessor complex. Nature 2004, 432:231-235

38. Bartel DP: MicroRNAs: genomics, biogenesis, mechanism, and function. Cell 2004, 116:281-297

39. Baek D, Villen J, Shin C, Camargo FD, Gygi SP, Bartel DP: The impact of microRNAs on protein output. Nature 2008, 455:64-71

40. Friedman RC, Farh KK, Burge CB, Bartel DP: Most mammalian mRNAs are conserved targets of microRNAs. Genome Res 2009, 19: 92-105

41. Xu W, Hui C, Yu SS, Jing C, Chan HC: MicroRNAs and cystic fibrosis: an epigenetic perspective. Cell Biol Int 2011, 35:463-466

42. Oglesby IK, Bray IM, Chotirmall SH, Stallings RL, O'Neill SJ, McElvaney NG, Greene CM: miR-126 is downregulated in cystic fibrosis airway epithelial cells and regulates TOM1 expression. J Immunol 2010, 184:1702-1709

43. Filipowicz W, Bhattacharyya SN, Sonenberg N: Mechanisms of posttranscriptional regulation by microRNAs: are the answers in sight? Nat Rev Genet 2008, 9:102-114

44. Brest P, Lapaquette P, Souidi M, Lebrigand K, Cesaro A, VouretCraviari V, Mari B, Barbry P, Mosnier JF, Hebuterne X, Harel-Bellan A, Mograbi B, Darfeuille-Michaud A, Hofman P: A synonymous variant in IRGM alters a binding site for miR-196 and causes deregulation of IRGM-dependent xenophagy in Crohn's disease. Nat Genet 2011, 43: 242-245

45. Di Leva G, Croce CM: miRNA profiling of cancer. Curr Opin Genet Dev 2013, 23:3-11

46. Leidinger P, Keller A, Meese E: MicroRNAs: important molecules in lung cancer research. Front Genet 2011, 2:104

47. Dweep H, Sticht C, Gretz N: In-silico algorithms for the screening of possible microRNA binding sites and their interactions. Curr Genomics 2013, 14:127-136

48. Peterson SM, Thompson JA, Ufkin ML, Sathyanarayana P, Liaw L, Congdon CB: Common features of microRNA target prediction tools. Front Genet 2014, 5:23 
49. Dweep H, Sticht C, Pandey P, Gretz N: miRWalk-database: prediction of possible miRNA binding sites by "walking" the genes of three genomes. J Biomed Inform 2011, 44:839-847

50. Cline MS, Smoot M, Cerami E, Kuchinsky A, Landys N, Workman C, Christmas R, Avila-Campilo I, Creech M, Gross B, Hanspers K, Isserlin R, Kelley R, Killcoyne S, Lotia S, Maere S, Morris J, Ono K, Pavlovic V, Pico AR, Vailaya A, Wang PL, Adler A, Conklin BR, Hood L, Kuiper M, Sander C, Schmulevich I, Schwikowski B, Warner GJ, Ideker T, Bader GD: Integration of biological networks and gene expression data using Cytoscape. Nat Protoc 2007, 2:2366-2382

51. El-Murr N, Abidi Z, Wanherdrick K, Svrcek M, Gaub MP, Fléjou JF, Hamelin R, Duval A, Lesuffleur T: MiRNA genes constitute new targets for microsatellite instability in colorectal cancer. PLoS One 2012, 7:e31862

52. Kasinski AL, Slack FJ: Epigenetics and genetics: microRNAs en route to the clinic: progress in validating and targeting microRNAs for cancer therapy. Nat Rev Cancer 2011, 11:849-864

53. Meola N, Gennarino VA, Banfi S: microRNAs and genetic diseases. Pathogenetics 2009, 2:7

54. Han M, Zheng Y: Comprehensive analysis of single nucleotide polymorphisms in human microRNAs. PLoS One 2013, 8:e78028

55. Abelson JF, Kwan KY, O'Roak BJ, Baek DY, Stillman AA, Morgan TM, Mathews CA, Pauls DL, Rasin MR, Gunel M, Davis NR, Ercan-Sencicek AG, Guez DH, Spertus JA, Leckman JF, Dure LSt, Kurlan R, Singer HS, Gilbert DL, Farhi A, Louvi A, Lifton RP, Sestan N, State MW: Sequence variants in SLITRK1 are associated with Tourette's syndrome. Science 2005, 310:317-320

56. Shiohama A, Sasaki T, Noda S, Minoshima S, Shimizu N: Molecular cloning and expression analysis of a novel gene DGCR8 located in the DiGeorge syndrome chromosomal region. Biochem Biophys Res Commun 2003, 304:184-190

57. Mukherji S, Ebert MS, Zheng GX, Tsang JS, Sharp PA, van Oudenaarden A: MicroRNAs can generate thresholds in target gene expression. Nat Genet 2011, 43:854-859

58. Gillen AE, Gosalia N, Leir SH, Harris A: MicroRNA regulation of expression of the cystic fibrosis transmembrane conductance regulator gene. Biochem J 2011, 438:25-32

59. Bhattacharyya S, Balakathiresan NS, Dalgard C, Gutti U, Armistead D, Jozwik C, Srivastava M, Pollard HB, Biswas R: Elevated miR-155 promotes inflammation in cystic fibrosis by driving hyperexpression of interleukin-8. J Biol Chem 2011, 286: 11604-11615

60. Marcet B, Chevalier B, Luxardi G, Coraux C, Zaragosi LE, Cibois M, Robbe-Sermesant K, Jolly T, Cardinaud B, Moreilhon C, GiovanniniChami L, Nawrocki-Raby B, Birembaut P, Waldmann R, Kodjabachian L, Barbry P: Control of vertebrate multiciliogenesis by miR-449 through direct repression of the Delta/Notch pathway. Nat Cell Biol 2011, 13:693-699

61. Megiorni F, Cialfi S, Dominici C, Quattrucci S, Pizzuti A: Synergistic post-transcriptional regulation of the Cystic Fibrosis Transmembrane conductance Regulator (CFTR) by miR-101 and miR-494 specific binding. PLoS One 2011, 6:e26601

62. Ramachandran S, Karp PH, Jiang P, Ostedgaard LS, Walz AE, Fisher JT, Keshavjee S, Lennox KA, Jacobi AM, Rose SD, Behlke MA, Welsh MJ, Xing Y, McCray PB Jr: A microRNA network regulates expression and biosynthesis of wild-type and DeltaF508 mutant cystic fibrosis transmembrane conductance regulator. Proc Natl Acad Sci U S A 2012, 109:13362-13367

63. Hassan F, Nuovo GJ, Crawford M, Boyaka PN, Kirkby S, NanaSinkam SP, Cormet-Boyaka E: MiR-101 and miR-144 regulate the expression of the CFTR chloride channel in the lung. PLoS One 2012, 7:e50837

64. Oglesby IK, Chotirmall SH, McElvaney NG, Greene CM: Regulation of cystic fibrosis transmembrane conductance regulator by microRNA-145, -223, and -494 is altered in $\Delta$ F508 cystic fibrosis airway epithelium. J Immunol 2013, 190:3354-3362
65. Megiorni F, Cialfi S, Cimino G, De Biase RV, Dominici C, Quattrucci S, Pizzuti A: Elevated levels of miR-145 correlate with SMAD3 down-regulation in cystic fibrosis patients. J Cyst Fibros 2013, 12:797-802

66. Viart V, Bergougnoux A, Bonini J, Varilh J, Chiron R, Tabary O, Molinari N, Claustres M, Taulan-Cadars M: Transcription factors and miRNAs that regulate fetal to adult CFTR expression change are new targets for cystic fibrosis. Eur Respir J 2015, 45:116-128

67. Amato F, Seia M, Giordano S, Elce A, Zarrilli F, Castaldo G, Tomaiuolo R: Gene mutation in microRNA target sites of CFTR gene: a novel pathogenetic mechanism in cystic fibrosis? PLoS One 2013, 8:e60448

68. Zhong T, Perelman JM, Kolosov VP, Zhou XD: MiR-146a negatively regulates neutrophil elastase-induced MUC5AC secretion from 16HBE human bronchial epithelial cells. Mol Cell Biochem 2011, 358:249-255

69. Guo X, Pace RG, Stonebraker JR, Commander CW, Dang AT, Drumm ML, Harris A, Zou F, Swallow DM, Wright FA, O'Neal WK, Knowles MR: Mucin variable number tandem repeat polymorphisms and severity of cystic fibrosis lung disease: significant association with MUC5AC. PLoS One 2011, 6:e25452

70. Fabbri E, Borgatti M, Montagner G, Bianchi N, Finotti A, Lampronti I, Bezzerri V, Dechecchi MC, Cabrini G, Gambari R: Expression of microRNA-93 and interleukin-8 during Pseudomonas aeruginosa-mediated induction of pro-inflammatory responses. Am J Respir Cell Mol Biol 2014, 50:1144-1155

71. Chen X, Ba Y, Ma L, Cai X, Yin Y, Wang K, Guo J, Zhang Y, Chen J, Guo X, Li Q, Li X, Wang W, Zhang Y, Wang J, Jiang X, Xiang Y, Xu C, Zheng P, Zhang J, Li R, Zhang H, Shang X, Gong T, Ning G, Wang J, Zen K, Zhang J, Zhang CY: Characterization of microRNAs in serum: a novel class of biomarkers for diagnosis of cancer and other diseases. Cell Res 2008, 18: 997-1006

72. Mitchell PS, Parkin RK, Kroh EM, Fritz BR, Wyman SK, Pogosova-Agadjanyan EL, Peterson A, Noteboom J, O'Briant KC, Allen A, Lin DW, Urban N, Drescher CW, Knudsen BS, Stirewalt DL, Gentleman R, Vessella RL, Nelson PS, Martin DB, Tewari M: Circulating microRNAs as stable blood-based markers for cancer detection. Proc Natl Acad Sci U S A 2008, 105: 10513-10518

73. Chung AC, Yu X, Lan HY: MicroRNA and nephropathy: emerging concepts. Int J Nephrol Renovasc Dis 2013, 6:169-179

74. Yu L, Todd NW, Xing L, Xie Y, Zhang H, Liu Z, Fang H, Zhang J, Katz RL, Jiang F: Early detection of lung adenocarcinoma in sputum by a panel of microRNA markers. Int J Cancer 2010, 127: $2870-2878$

75. Markou A, Liang Y, Lianidou E: Prognostic, therapeutic and diagnostic potential of microRNAs in non-small cell lung cancer. Clin Chem Lab Med 2011, 49:1591-1603

76. Shah AK, Saunders NA, Barbour AP, Hill MM: Early diagnostic biomarkers for esophageal adenocarcinoma: the current state of play. Cancer Epidemiol Biomarkers Prev 2013, 22:1185-1209

77. Sita-Lumsden A, Dart DA, Waxman J, Bevan CL: Circulating microRNAs as potential new biomarkers for prostate cancer. Br J Cancer 2013, 108:1925-1930

78. Sanfiorenzo C, Ilie MI, Belaid A, Barlesi F, Mouroux J, Marquette CH, Brest P, Hofman P: Two panels of plasma microRNAs as non-invasive biomarkers for prediction of recurrence in resectable NSCLC. PLoS One 2013, 8:e54596

79. Takamizawa J, Konishi H, Yanagisawa K, Tomida S, Osada H, Endoh H, Harano T, Yatabe Y, Nagino M, Nimura Y, Mitsudomi T, Takahashi T: Reduced expression of the let-7 microRNAs in human lung cancers in association with shortened postoperative survival. Cancer Res 2004, 64:3753-3756

80. Keller A, Leidinger P, Bauer A, Elsharawy A, Haas J, Backes C, et al: Toward the blood-borne miRNome of human diseases. Nat Methods 2011, 8:841-843 
81. Ranade AR, Cherba D, Sridhar S, Richardson P, Webb C, Paripati A, Bowles B, Weiss GJ: MicroRNA 92a-2*: a biomarker predictive for chemoresistance and prognostic for survival in patients with small cell lung cancer. J Thorac Oncol 2010, 5:1273-1278

82. Rupani H, Sanchez-Elsner T, Howarth P: MicroRNAs and respiratory diseases. Eur Respir J 2013, 41:695-705

83. Seto AG: The road toward microRNA therapeutics. Int J Biochem Cell Biol 2010, 42:1298-1305

84. Davies JC, Alton EWFW: Gene therapy for cystic fibrosis. Proc Am Thorac Soc 2010, 7:408-414

85. Zhang JT, Jiang XH, Xie C, Cheng H, Da Dong J, Wang Y, Fok KL, Zhang XH, Sun TT, Tsang LL, Chen H, Sun XJ, Chung YW, Cai ZM, Jiang WG, Chan HC: Downregulation of CFTR promotes epithelial-to-mesenchymal transition and is associated with poor prognosis of breast cancer. Biochim Biophys Acta 2013, 1833: $2961-2969$

86. Johnson LG, Olsen JC, Sarkadi B, Moore KL, Swanstrom R, Boucher RC: Efficiency of gene transfer for restoration of normal airway epithelial function in cystic fibrosis. Nat Genet 1992, 2: $21-25$

87. Johnson LG, Boyles SE, Wilson J, Boucher RC: Normalization of raised sodium absorption and raised calcium-mediated chloride secretion by adenovirus-mediated expression of cystic fibrosis transmembrane conductance regulator in primary human cystic fibrosis airway epithelial cells. J Clin Invest 1995, 95: $1377-1382$

88. Goldman MJ, Yang Y, Wilson JM: Gene therapy in a xenograft model of cystic fibrosis lung corrects chloride transport more effectively than the sodium defect. Nat Genet 1995, 9:126-131

89. Ramalho AS, Beck S, Meyer M, Penque D, Cutting GR, Amaral MD: Five percent of normal cystic fibrosis transmembrane conductance regulator mRNA ameliorates the severity of pulmonary disease in cystic fibrosis. Am J Respir Cell Mol Biol 2002, 27:619-627

90. Dannhoffer L, Blouquit-Laye S, Regnier A, Chinet T: Functional properties of mixed cystic fibrosis and normal bronchial epithelial cell cultures. Am J Respir Cell Mol Biol 2009, 40:717-723

91. Ruffin M, Voland M, Marie S, Bonora M, Blanchard E, BlouquitLaye S, Naline E, Puyo P, Le Rouzic P, Guillot L, Corvol H, Clement A, Tabary O: Anoctamin 1 dysregulation alters bronchial epithelial repair in cystic fibrosis. Biochim Biophys Acta 2013, 1832: 2340-2351

92. Janssen HL, Reesink HW, Lawitz EJ, Zeuzem S, RodriguezTorres M, Patel K, van der Meer AJ, Patick AK, Chen A, Zhou Y, Persson R, King BD, Kauppinen S, Levin AA, Hodges MR: Treatment of HCV infection by targeting microRNA. N Engl J Med 2013, 368:1685-1694 